Research Article

\title{
Postfire Safety Investigation on Prestressed RPC Beams after Exposure to Elevated Temperatures
}

\author{
Yan Kai $\mathbb{D}^{1}{ }^{1}$ Zhang Yao, ${ }^{1}$ Cai Hao, ${ }^{1}$ Fan Lili, ${ }^{2}$ and Xin Zhang ${ }^{1}$ \\ ${ }^{1}$ Key Lab of Building Structural Retrofitting and Underground Space Engineering of the Ministry of Education, \\ Shandong Jianzhu University, Jinan, China \\ ${ }^{2}$ Shandong Institute of Mechanical Design, Jinan, China \\ Correspondence should be addressed to Yan Kai; yankai@sdjzu.edu.cn
}

Received 2 January 2020; Accepted 2 April 2020; Published 8 May 2020

Academic Editor: Hiroshi Yoshihara

Copyright ( 92020 Yan Kai et al. This is an open access article distributed under the Creative Commons Attribution License, which permits unrestricted use, distribution, and reproduction in any medium, provided the original work is properly cited.

\begin{abstract}
Since the postfire safety of prestressed RPC beams after exposure to elevated temperatures needs to be studied and proved, this paper prepares eight smart prestressed RPC beams with intelligent sensors built in to monitor the internal temperature, force, and strain. The residual bearing tests after fire are carried out. The failure process of the beams under static load with different fire durations cover thickness of tendons, load ratio, bonded and unbonded tendons, and partial prestressing ratio, which are investigated. The load-deflection curves, crack distributions and developments, and strain variations are obtained, in addition to the damage mechanism and failure mode of the beams. The results show that the load-deflection curve of the prestressed RPC beam after fire has obviously three polylines, and the deflection points are where the cracks expand and the tendons yield. The failure procedure is the same as that of under-reinforced beams, while the height of the crushing zone is much lower than that of the balanced-reinforced beam at room temperature. The whole span deformation demonstrates a strong catenary effect, and the midspan deflection is approximately $1 / 40$ of the effective span. The postfire safety of the bonded prestressed RPC beams is superior to that of unbonded prestressed RPC beams. The test results of this paper provide a basis for the safety performance evaluation and control of prestressed RPC beams after fire.
\end{abstract}

\section{Introduction}

Reactive powder concrete (RPC) has extremely high compressive strength and excellent durability [1], especially with significant application prospects in large-span, high-rise, and underground buildings $[2,3]$. Combining RPC with high-strength prestressed tendons to form prestressed RPC beams can leverage the excellent performance of both products and achieve reduction of the weight, expansion of the span, and increase of the durability of the structure. Under the high temperatures of fire, the material properties of steel reinforcement and concrete are greatly attenuated, the bearing capacity of the components is significantly weakened, and the internal forces are redistributed inside the structure, which may lead to serious damage and even the collapse of the structure [4-9]. The probability for concrete beams to exhibit normal section bending fracture and collapse is low, so the main problem lies in how to evaluate the damage and safety of buildings after fire [10-13]. The residual bearing capacity and safety assessment of the postfire structure are directly related to the postfire treatment of the building, including continued use, strengthening design, and strengthening construction scheme. Even if there is no significant visible damage to a prestressed concrete structure in fire, the mechanical properties of the concrete, tendons, and steel bars can be degraded, which brings hidden dangers to the safety performance of the prestressed concrete structure [14-17]. Currently, research results on the mechanical properties of prestressed RPC beams after fire have not been reported. As the main load-bearing component, prestressed RPC beams lack effective fire-resistant design methods. Therefore, it is of great theoretical significance and practical value to study the mechanical properties, residual bearing properties, and postfire safety properties of prestressed RPC beams. 
At present, some research studies have been carried out on the mechanical properties of RPC and prestressed tendons after exposure to elevated temperatures. Zheng et al. [18-20] studied the impact of parameters, such as temperature $\left(0-900^{\circ} \mathrm{C}\right)$, fiber type and dosage, constant-temperature time, and heating speed, on the mechanical properties of RPC after exposure to elevated temperatures. The properties included the RPC cube compressive strength, axial compressive strength, tensile strength, elastic modulus, peak strain and toughness, and corresponding calculation formulas obtained by regression analysis. Peng et al. [21, 22] experimentally studied the residual mechanical properties and spalling behavior of RPC with different steel fiber dosages. Tai et al. [23] tested the mechanical properties of steel fiber RPC after exposure to high temperatures of 200-800 C. Liu and Huang [24] studied the mechanical properties of RPC with high mobility after exposure to a high temperature and concluded that the residual compressive strength of RPC decreased with the increase in the fire duration. Day et al. [25] conducted constant-load heating and high-temperature creep tests on prestressed steel wire; the mechanical properties of prestressed steel wire and tendons under and after exposure to high temperatures were investigated. Guo and Shi [26] conducted constant-temperature loading tests on steel bars of different grades and proposed the formulas for calculating the ultimate tensile strength and yield strength of steel bars at high temperatures. Hou et al. [27] studied the mechanical properties of tendons in fire, discussed the change rules of mechanical indexes such as the strength and elastic modulus, and established the stress-strain relationship equation of tendons during high temperature.

Given the fact that the safety performance of prestressed RPC beams after fire needs to be studied, this paper designed and manufactured eight smart prestressed RPC beams with intelligent sensors built in to monitor the internal temperature, force, and strain. The constant-load heating tests under ISO 834 [28] standard heating condition are carried out. On this basis, the static load test after fire is conducted, and the postfire safety of the smart prestressed RPC beams is studied. The results provide a basis for the safety evaluation and control of prestressed RPC beams after fire.

\section{Fire Safety Experiments}

2.1. Design of Specimens. Six bonded prestressed RPC beams and two unbonded prestressed RPC beams have been designed and fabricated. The beam section size is $250 \mathrm{~mm} \times 350 \mathrm{~mm}$, the total length is $6500 \mathrm{~mm}$, and the calculated span is $6000 \mathrm{~mm}$. The test parameters are the cover thickness of tendons $C_{\mathrm{p}}$, load ratio, partial prestressing ratio (PPR), and type of tendons (bonded and unbonded), as shown in Table 1.

The tendons are arranged in a three-section parabola, extending along the neutral axis at both ends of the support. The horizontal distance between the reverse bending point and the support is 0.15 times the calculated span. The longitudinal rebar on the top of the beam is 218 , the longitudinal rebar on the bottom of the beam is 222 , and the cover thickness of the longitudinal rebar is $25 \mathrm{~mm}$. The flexural capacities for beams in Table 1 are theoretical values, which were calculated using the method from Zheng et al. [29]. In the formula for calculating flexural capacities, the tensile force provided by RPC in the tension zone was introduced. Taking PRPCB1 and UPRPCB1 as examples, the details of dimensions and reinforcements are shown in Figure 1.

2.2. Materials and Mix Proportions. The RPC raw materials are as follows: P.O. 52.5 Portland cement; Silica fume with $92.17 \% \mathrm{SiO}_{2}$ of specific surface area $24200 \mathrm{~m}^{2} / \mathrm{kg}$; $\mathrm{S} 75$ grade slag powder of specific surface area $450 \mathrm{~m}^{2} / \mathrm{kg}$; glass microbead fly ash of specific surface area $600 \mathrm{~m}^{2} / \mathrm{kg}$; natural fine river sand of fineness modulus 1.92 and particle size 1.0 3.0 mm; type I plain copper-plated steel fiber of length $13 \mathrm{~mm}$ and equivalent diameter $0.22 \mathrm{~mm}$; and liquid polycarboxylic acid superplasticizer containing $40 \%$ solids. The mix ratio is shown in Table 2 . The cube specimens have a geometry of $100 \times 100 \times 100 \mathrm{~mm}^{3}$ in material strength test, and the cube compressive strength of the RPC is $160 \mathrm{MPa}$.

The tendon system adopts $1860 \mathrm{MPa}$ low-relaxation steel strands with a diameter of $15.2 \mathrm{~mm}, \mathrm{BM} 15-3$ clip anchor, and galvanized flat metal bellows (section size: $65 \mathrm{~mm} \times 25 \mathrm{~mm}$ ). The longitudinal rebars and stirrups are HRB 400 hot rolled steel bars; the measured yield strength and ultimate strength are shown in Table 3.

2.3. Fire Test Setup. The fire test has been carried out in a large horizontal structure fire furnace. The length $\times$ width $\times$ height of the test furnace is $6.0 \mathrm{~m} \times 5.0 \mathrm{~m} \times 1.5 \mathrm{~m}$. The specimens have been heated under a constant load; the two sides and the bottom have been exposed to fire. The specimens are simply supported at both ends. The concentrated load (loaded to the predetermined load level by the hydraulic jack and kept constant) has been applied at the three deflection points. The furnace has been heated according to the ISO834 standard heating curve, and the fire test setup is illustrated in Figure 2. PRPCB1 PRPCB4 are the first furnace, which is exposed to fire for $150 \mathrm{~min}$; PRPCB5, PRPCB6, UPRPCB1, and UPRPCB2 are the second furnace, which is exposed to fire for $160 \mathrm{~min}$. The comparison between the measured furnace temperatures and the ISO834 standard heating curve is shown in Figure 3.

2.4. Fire Test Results. The specimen morphology after exposure to the fire is shown in Figure 4. All the specimens have different degrees of bending cracks, of which the main cracks are located in the mid-span region. During the process of postfire cooling, the material properties of the RPC and reinforcements are partially restored, and the deflection of the beams tended to recover. After natural cooling at room temperature, the specimens all have residual deflections. The specimens maintained good volume integrity, with only minor bursts occurring locally. The burst area is $2.52 \%$ of the fire area, and the burst depth is $3 \sim 12 \mathrm{~mm}$. The bursting is random and because the specimen bursts 
TABLE 1: Parameters of specimens.

\begin{tabular}{|c|c|c|c|c|c|c|c|c|c|}
\hline No. & $\begin{array}{c}\text { Cover thickness } \\
\text { of tendons } C_{\mathrm{p}}(\mathrm{mm})\end{array}$ & Load ratio & PPR & $A_{\mathrm{p}}$ & $f_{\mathrm{cu}}(\mathrm{MPa})$ & $f_{\mathrm{t}}(\mathrm{MPa})$ & $\begin{array}{c}\text { Bending } \\
\text { capacities }(\mathrm{kN} \cdot \mathrm{m})\end{array}$ & Preload $(\mathrm{kN})$ & Prestress $(\mathrm{kN})$ \\
\hline PRPCB1 & 35 & 0.3 & 0.69 & $3 \mathrm{~b} \Phi^{\mathrm{S}} 15$ & 165.17 & 12.29 & 107.12 & 96.93 & 581.72 \\
\hline PRPCB2 & 35 & 0.5 & 0.69 & $3 \mathrm{~b} \Phi^{\mathrm{S}} 15$ & 162.94 & 11.40 & 181.65 & 171.45 & 581.75 \\
\hline PRPCB3 & 45 & 0.5 & 0.60 & $2 \mathrm{~b} \Phi^{\mathrm{S}} 15$ & 158.03 & 11.16 & 144.07 & 133.87 & 387.81 \\
\hline PRPCB4 & 45 & 0.5 & 0.69 & $3 \mathrm{~b} \Phi^{\mathrm{S}} 15$ & 176.77 & 12.51 & 179.73 & 169.54 & 581.70 \\
\hline PRPCB5 & 55 & 0.3 & 0.69 & $3 \mathrm{~b} \Phi^{\mathrm{S}} 15$ & 166.42 & 12.38 & 102.41 & 92.20 & 581.73 \\
\hline PRPCB6 & 55 & 0.5 & 0.69 & $3 \mathrm{~b} \Phi^{\mathrm{S}} 15$ & 165.90 & 12.77 & 173.89 & 163.62 & 581.72 \\
\hline UPRPCB1 & 45 & 0.5 & 0.69 & $3 \mathrm{U} \Phi^{\mathrm{S}} 15$ & 160.87 & 11.65 & 177.56 & 167.38 & 581.75 \\
\hline UPRPCB2 & 55 & 0.5 & 0.69 & $3 \mathrm{U} \Phi^{\mathrm{S}} 15$ & 162.15 & 11.93 & 173.82 & 163.61 & 581.71 \\
\hline
\end{tabular}

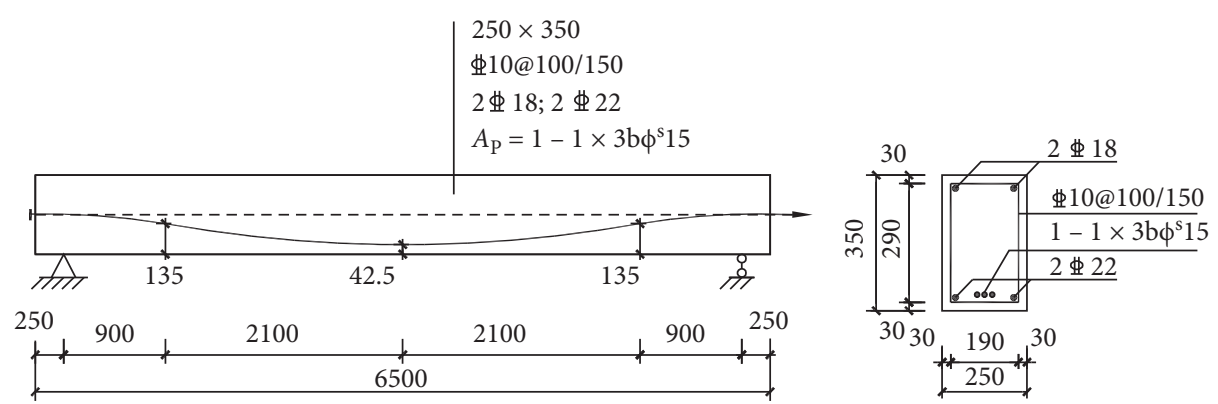

(a)
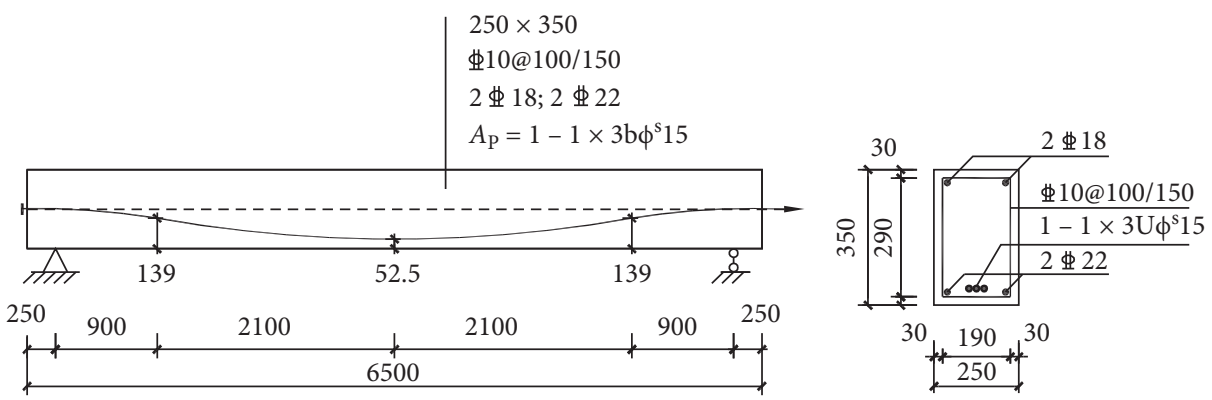

(b)

Figure 1: Dimensions and details of two example specimens. (a) PRPCB1 and (b) UPRPCB1.

TABle 2: Mix ratio of RPC.

\begin{tabular}{lccccccc}
\hline $\begin{array}{l}\text { Water-binder } \\
\text { ratio }\end{array}$ & Cement & $\begin{array}{c}\text { Silica } \\
\text { fume }\end{array}$ & $\begin{array}{c}\text { Slag } \\
\text { powder }\end{array}$ & $\begin{array}{c}\text { Fly } \\
\text { ash }\end{array}$ & $\begin{array}{c}\text { Fine } \\
\text { sand }\end{array}$ & $\begin{array}{c}\text { Amount of water reducer in solid } \\
\text { state }\end{array}$ & $\begin{array}{c}\text { Steel fiber volume content } \\
(\%)\end{array}$ \\
\hline 0.2 & 1 & 0.3 & 0.2 & 0.2 & 1.2 & 0.04 & 2 \\
\hline
\end{tabular}

TABLE 3: Mechanical properties of steel bars.

\begin{tabular}{lccc}
\hline Species & Yield strength (conditional yield strength) $(\mathrm{MPa})$ & Ultimate strength (MPa) & Proportional ultimate strength (MPa) \\
\hline 10 & 487.33 & 657.49 & - \\
18 & 485.90 & 644.83 & - \\
22 & 484.51 & 660.12 & - \\
$\Phi^{\mathrm{S}} 15$ & 1726.87 & 1932.94 & 1455.07 \\
\hline
\end{tabular}

slightly under fire has little influence on the temperature field of the specimens and the degradation amplitude of the internal material properties. Thus, the test data after fire deserves reference.

The internal temperature monitoring positions are described in Figures 5(a)-5(c), showing the change curves of the temperature with respect to the fire time at each monitoring point of PRPCB1 and UPRPCB1, respectively. $\mathrm{RPC}$ is a thermally inert material, and the transient heat in the beam conforms to the nonlinear transfer law of the secondary parabolic type, forming an inhomogeneous temperature field. With the increase in the fire time, the 


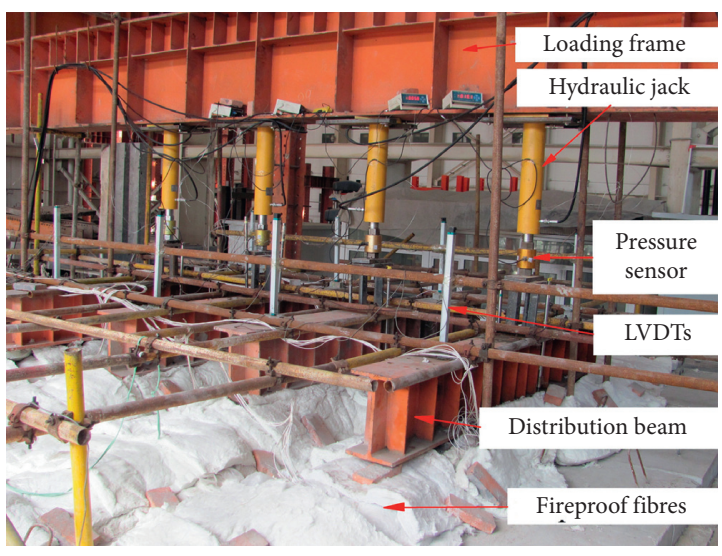

(a)

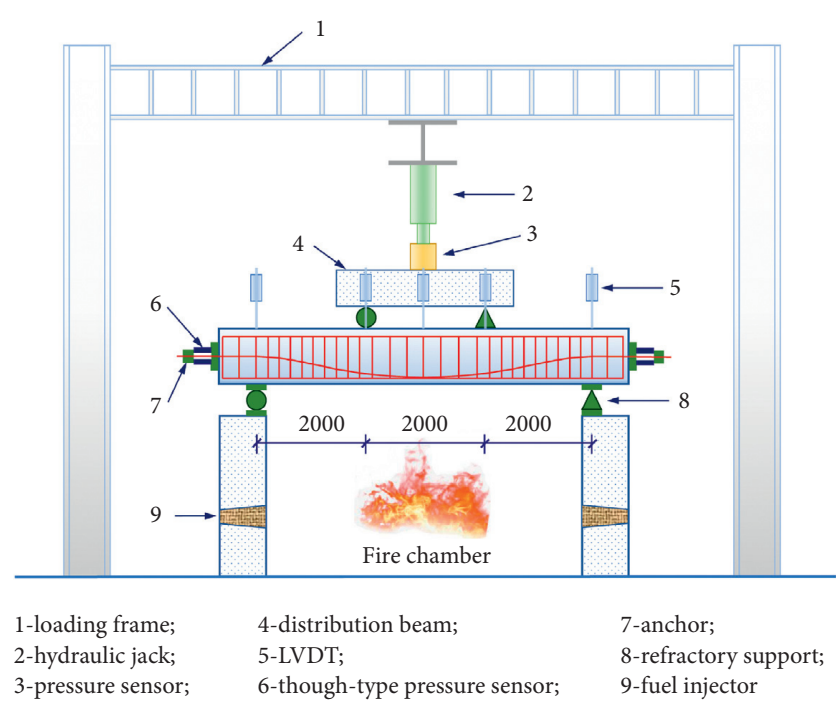

(b)

Figure 2: Fire test setup. (a) Lab view of test setup. (b) Test setup sketch.

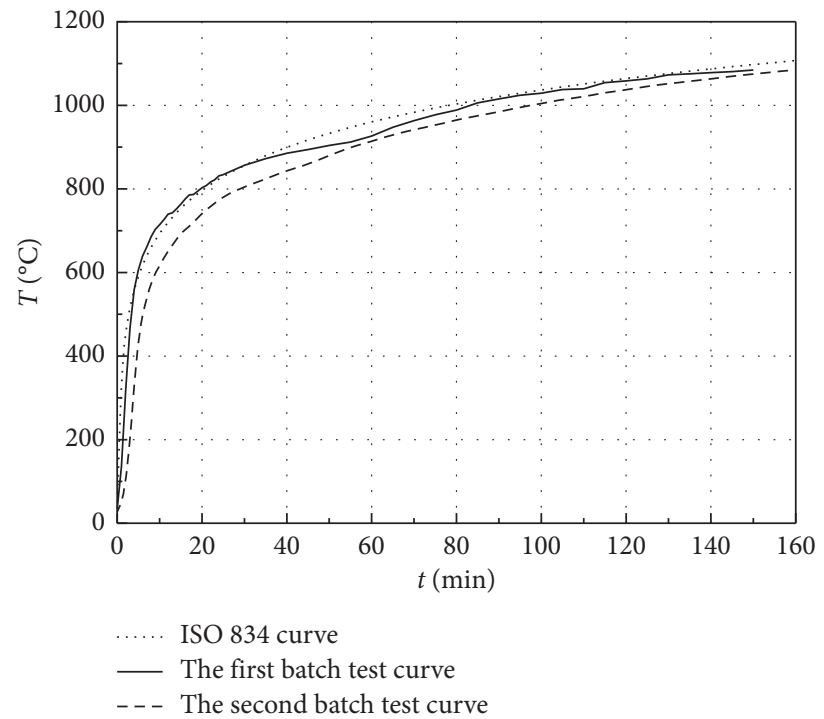

Figure 3: Temperature-fire curves of fire furnace.

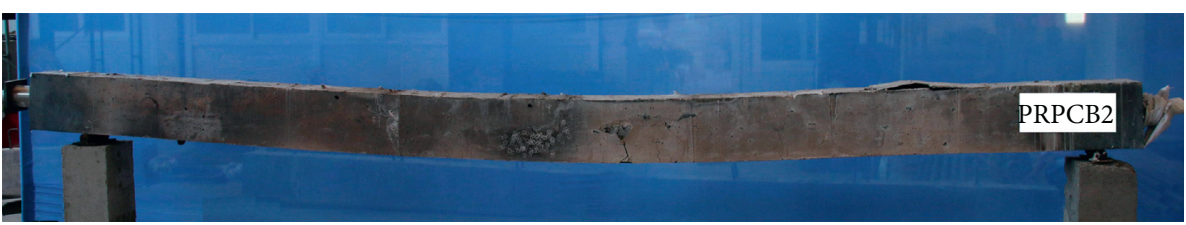

(a)

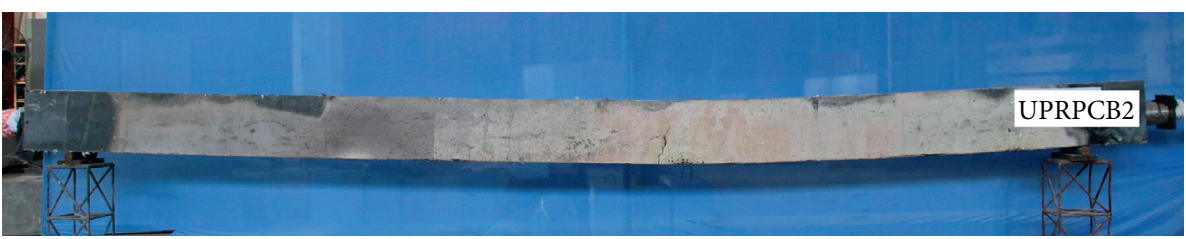

(b)

FIgURE 4: The specimen morphology after fire. (a) PRPCB2. (b) UPRPCB2. 

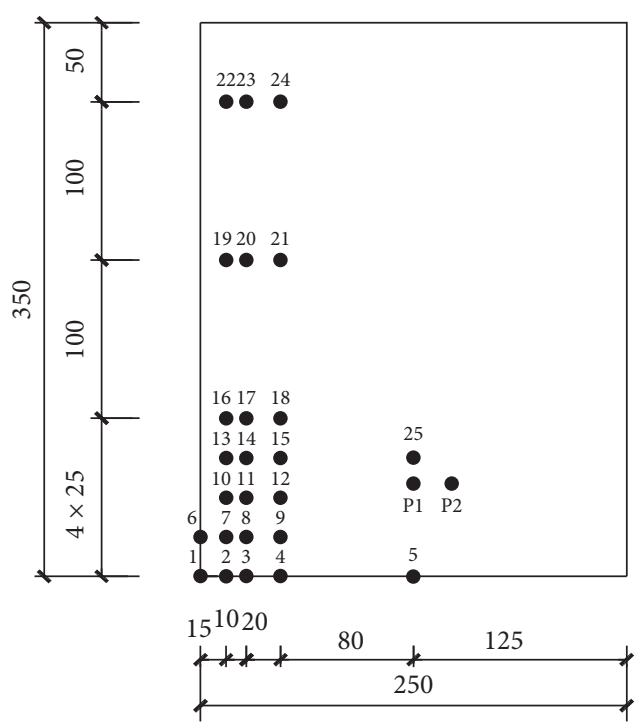

(a)
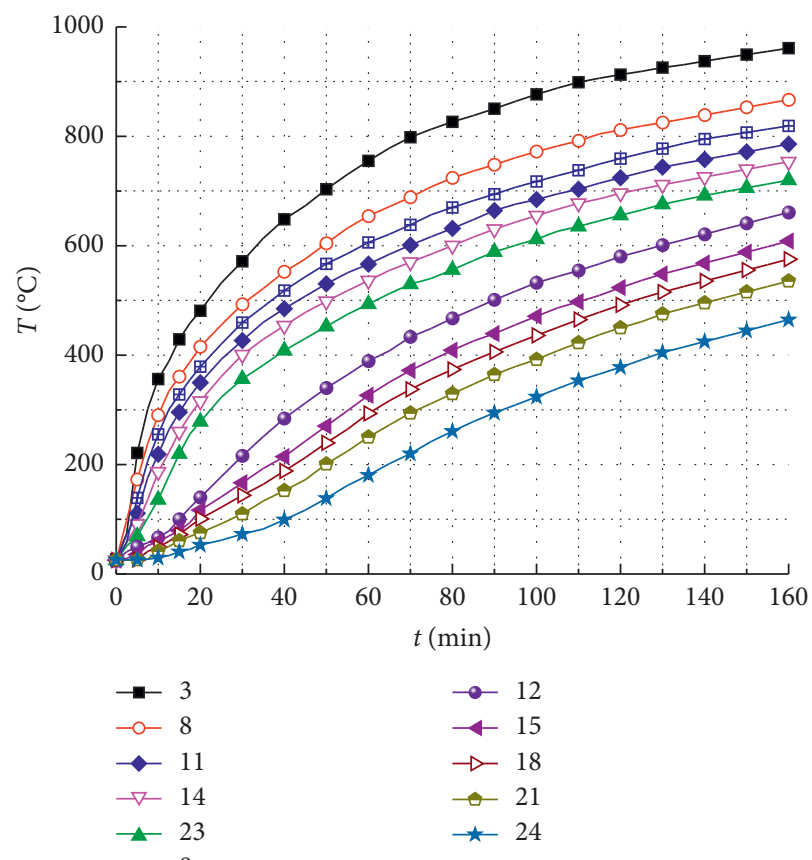

(c)

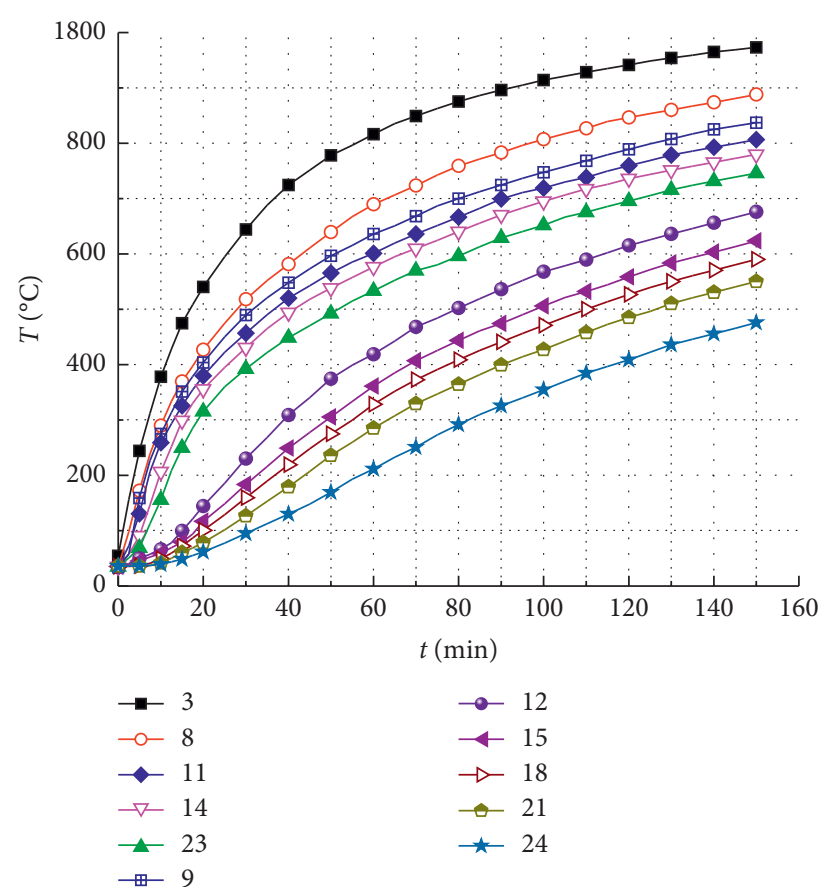

(b)
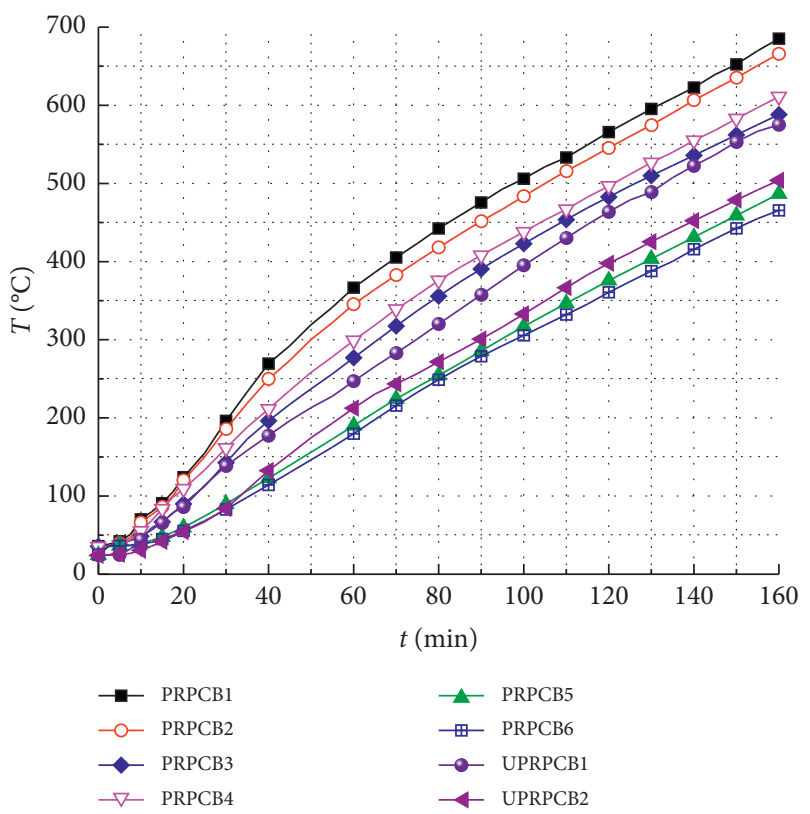

(d)

FIGURE 5: The temperature-fire time curves for the specimens. (a) Internal temperature monitoring points. (b) PRPCB1. (c) UPRPCB1. (d) Tendons.

internal temperature of the specimen increases nonlinearly. The closer the measurement to the fire surface, the larger the temperature gradient and the faster the rise in heating. The further away from the fire surface, the slower the rise in heating. Due to the same temperature environments in the furnace test, the internal temperature-time curve of each specimen has the same variation law. Figure 5(d) shows the change curve of the prestressed bar temperature for all fire specimens.

\section{Residual Bearing Capacity Tests after Fire}

3.1. Postfire Test Setup. The setup for the static load test of the prestressed RPC beams after fire is illustrated in Figure 6. 


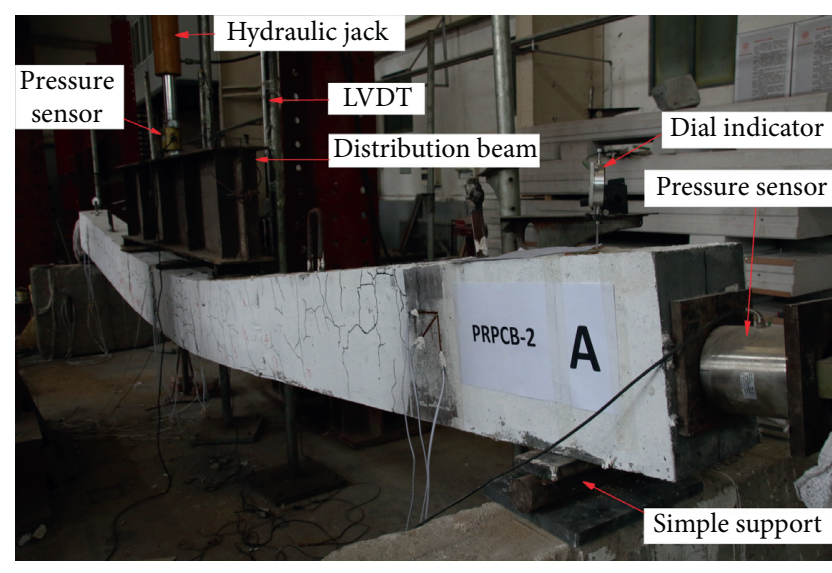

Figure 6: Postfire test setup.

The three-point loading approach is adopted. The pressure is applied by the hydraulic jacks and transferred to the two loading points by a distribution beam. A preload of $5 \mathrm{kN}$ is applied before formal loading; the beam is unloaded to zero after the formal loading. In the initial stage of formal loading, a load control is adopted to carry out graded loading with an increment of $5 \mathrm{kN}$. The load holding time of each stage is $3 \mathrm{~min}$, and the load value of each stage is no more than $20 \%$ of the normal load value. When the external load value is close to the ultimate load, the displacement control is adopted such that every $5 \mathrm{~mm}$ increase in the midspan displacement occurs for one grade.

3.2. Instrumentation. The displacement increment and concrete stress of the prestressed RPC beams at the midspan and the ends have been measured. The specimens are uniformly painted with lime after exposure to a fire. Before loading in the test, concrete strain gauges have been pasted; these are $120 \Omega$ foil type resistance strain gauges. Five strain gauges have been pasted transversely and uniformly every $25 \mathrm{~mm}$ at the edge of the midspan of both top and bottom sides of the specimens. Two strain gauges have been pasted every $60 \mathrm{~mm}$ at the trailing edge of the position where the large crack occurred after the fire. A $45^{\circ}$ paste triaxial strain rosette has been pasted $250 \mathrm{~mm}$ from the tension (or anchor) ends of both ends of the specimens, as shown in Figure 7.

The specimen deformation measurement points are arranged at the midspan, trisection loading points, and supports of the longitudinal axis of the beam. The displacements at the triequally divided loading point and midspan have changed substantially. The LVDT displacement meter with a measuring range of $\pm 250 \mathrm{~mm}$ has been adopted. At the supports, the displacement has been measured with a shockproof pointer dial meter to eliminate the influence of the beam end displacement on the deformation of the specimens.

\section{Residual Bearing Capacity Test Results}

4.1. Test Procedure. Before testing, the exposed surfaces of the specimens have some phenomena such as bursting, bulging and peeling, and pockmarked surfaces. The color appears gray and white. With the increase of the section height, the colors of other concrete components gradually decrease and tend to be light gray, among which the antiarch phenomenon appears on PRPCB6. At the early stage of the loading process, the specimens do not produce any obvious sounds. At the later stage, the midspan displacement of the beams increases rapidly. The steel fiber inside the beams presents rustling sounds, which are the sounds of steel fibers pulling out from the RPC substrate and of the steel fibers breaking. When the loading is about to stop, the concrete at the edge of the compression zone of the specimens is crushed and the midspan deformation of the beams continues to increase while the bearing load begins to decrease. Taking PRPCB2 as an example, the crack development is not obvious at the initial loading, but it is accompanied by the internal rustle of the beam body. When the external load reaches $140 \mathrm{kN}$, a new vertical crack appears in the middle span with a width of $0.05 \mathrm{~mm}$ and a length of $5 \mathrm{~cm}$. No obvious crack appears in the shear span. When the loading reaches $192 \mathrm{kN}$, three vertical main cracks in the pure bending section appear, with the maximum crack width of $6 \mathrm{~mm}$ and the average parallel distance of $13 \mathrm{~cm}$. At the $240 \mathrm{kN}$ loading, two main cracks in the pure bending section widen to $9 \mathrm{~mm}$. As the load continues to $276 \mathrm{kN}$, according to the displacement control, the prestressed tendon shrinks and the width of the main cracks increases rapidly and extends upward to the top of the beam. This causes the specimen to lose its bearing capacity instantly. As the external load reading falls back to $270 \mathrm{kN}$, the load reading is kept constant with continuous loading, while the midspan displacement increases from $250 \mathrm{~mm}$ to $260 \mathrm{~mm}$. At this time, no significant development of oblique cracks has been observed in the shear span. Compared with room temperature conditions, the failure pattern of the prestressed RPC beams after fire has no obvious uncracked stage; they bear loads with cracks and then fail after the steel bars yield.

The ultimate loads applied on PRPCB1-6 are $226.5 \mathrm{kN}$, $273 \mathrm{kN}, 207 \mathrm{kN}, 161.9 \mathrm{kN}, 201.7 \mathrm{kN}$, and $251.2 \mathrm{kN}$. The PRPCB4 specimen suffers the most serious damage with the maximum crack width up to $80 \mathrm{~mm}$. UPRPCB1 and UPRPCB2 fracture suddenly, and their ultimate bearing capacity has been reduced after the fire. The relative slippage occurs between the unbonded tendons and the RPC in the longitudinal direction. The tensile capacity of the unbounded tendons cannot be fully exerted: its bearing capacity is approximately $50 \%$ of the bonded prestressed RPC beams.

4.2. Midspan Deflections. Under fire, six of the beam specimens show residual deformation of different degrees. The exceptions are that the PRPCB2 deformation is not obvious and PRPCB6 presents an antiarch. Among the six, there is an obvious bottom-up main crack near the tensioning end of PRPCB4, of which the maximum crack width before loading is $25 \mathrm{~mm}$. PRPCB4 has the minimum ultimate load among the bonded prestressed RPC beams. The antiarch value of the PRPCB6 specimen is shown in Figure 8, which is used to calculate the midspan deflection increment that is postfire static load. 


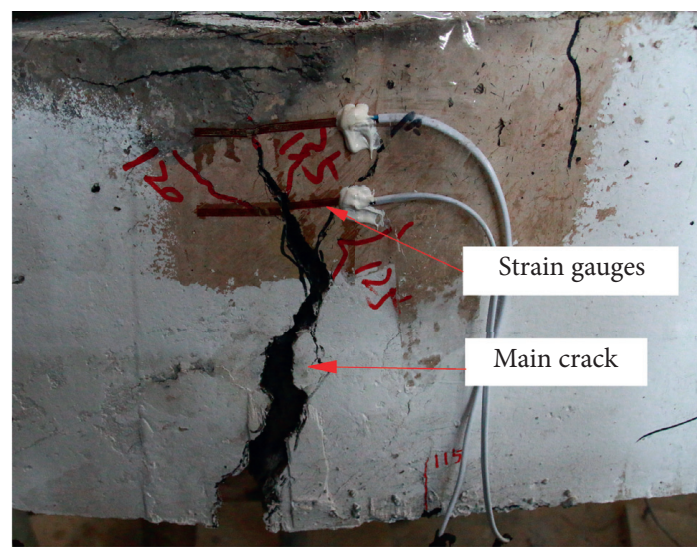

(a)

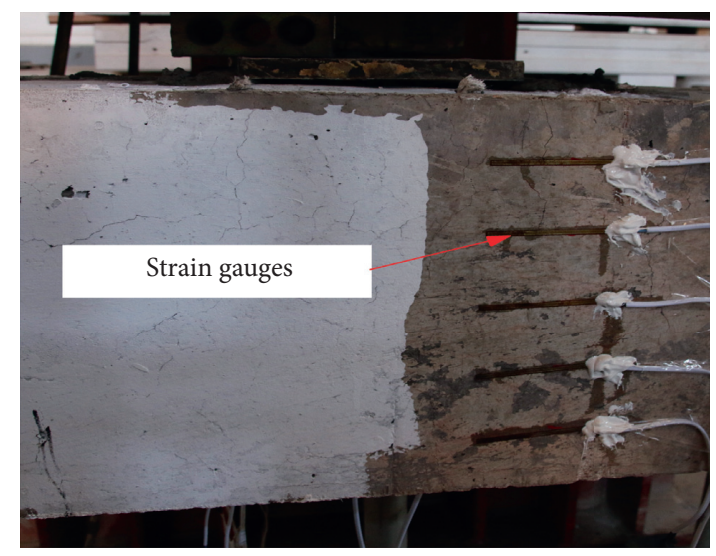

(b)

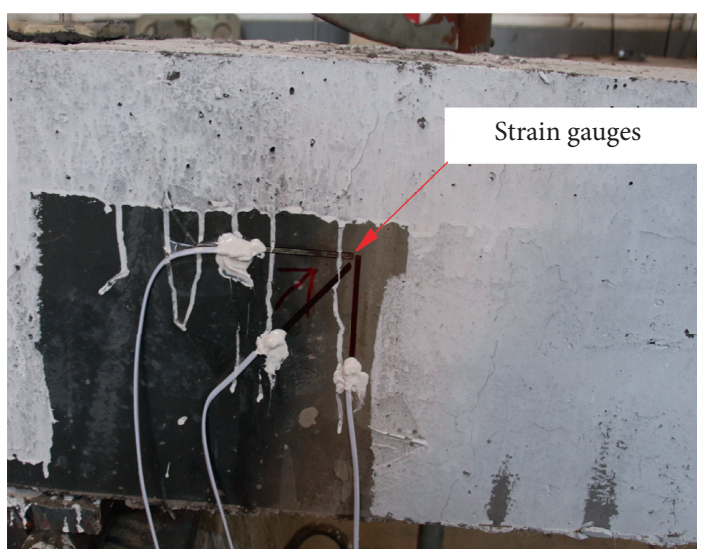

(c)

Figure 7: Strain monitoring. (a) Near the crack. (b) Midspan. (c) Near the support.

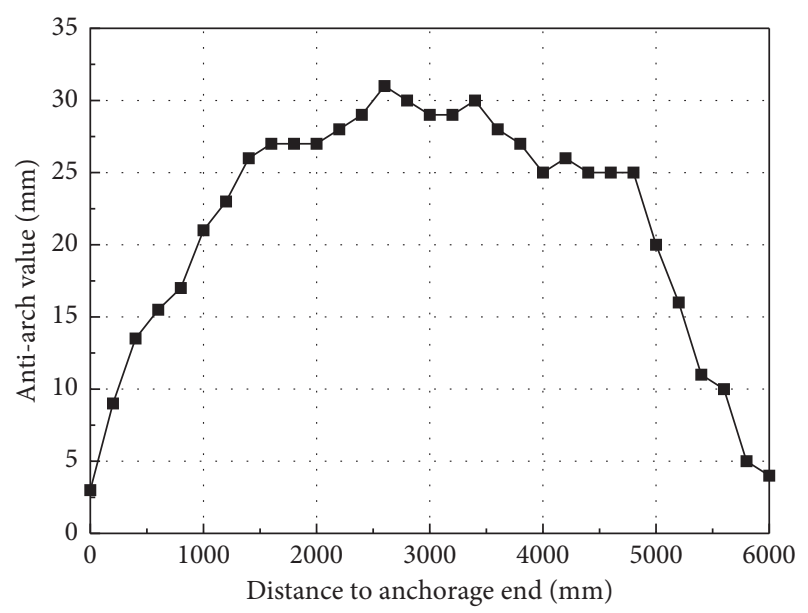

Figure 8: The antiarch value of PRPCB6 after fire.

The measurement of the midspan deflection starts at the position where the specimen is loaded to the proposed load at room temperature; this measurement is oriented with the positive direction downwards. The measured load-midspan deflection curve of each specimen is shown in Figure 9. Due to the prestress inside the beam, the load-midspan displacement change is divided into three stages. It shows a linear development trend from the beginning of the loading to the beginning of the RPC concrete crack expansion. After the crack propagation occurs, the slope of the load-midspan deflection curve gradually decreases with the increase of the midspan deflection, showing an obvious nonlinear characteristic. When the peak load is reached, the specimen enters the failure stage, and the curve tends to be stable with some parts showing a downward trend. The abovementioned three stages have significant turning points. By comparing the temperature field under fire for various beams, it appears that an elevated temperature has a great influence on the deformation performance of prestressed RPC beams. The longer the fire time at the same temperature, the greater the deflection of the specimens after the fire. The midspan deflection $\delta$ corresponding to the ultimate load is about $1 / 40$ of the effective span $l$, as shown in Figure 10, far more than 1/ 150 of the corresponding midspan deflection that occurs at room temperature.

4.3. Prestress and Strain Variety. Figure 11 shows the prestress versus displacement increment curves of tendons in specimens. Prestress at the end of the bonded prestressed beams performed no evident change during the static load test. The cover thickness of tendons $C_{\mathrm{p}}$ is more than $135 \mathrm{~mm}$ in the region from the contraflexural point to the support 


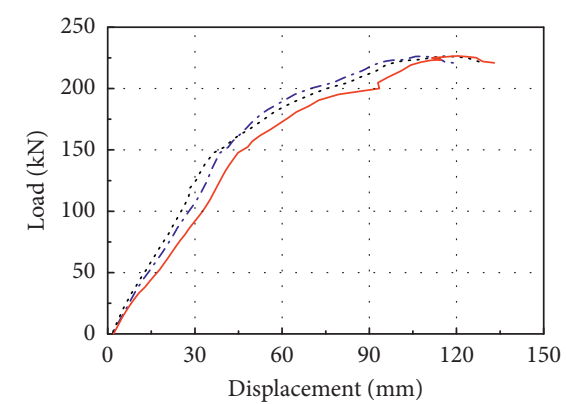

...- Three-point near anchorage

..... Three-point away anchorage

$$
\text { — Mid-span }
$$

(a)

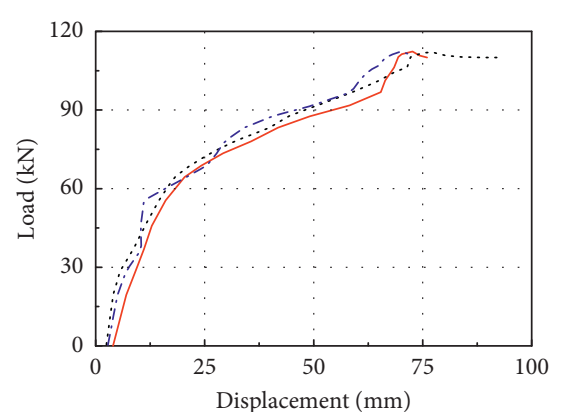

_ Mid-span

..... Three-point away anchorage -..- Three-point near anchorage

(d)

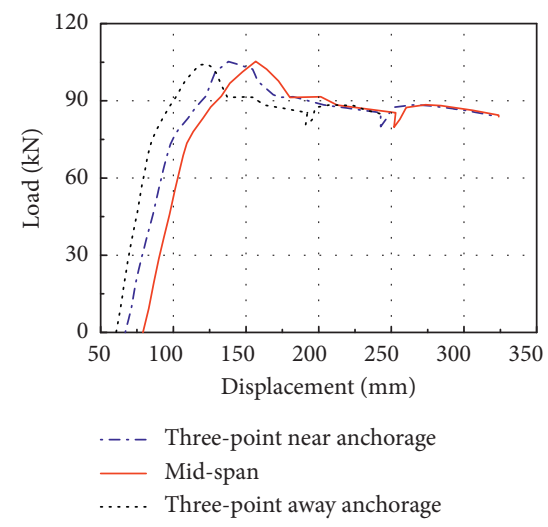

(g)

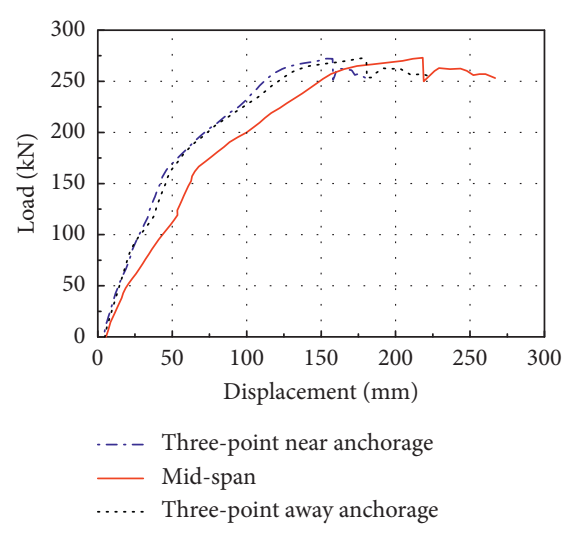

(b)

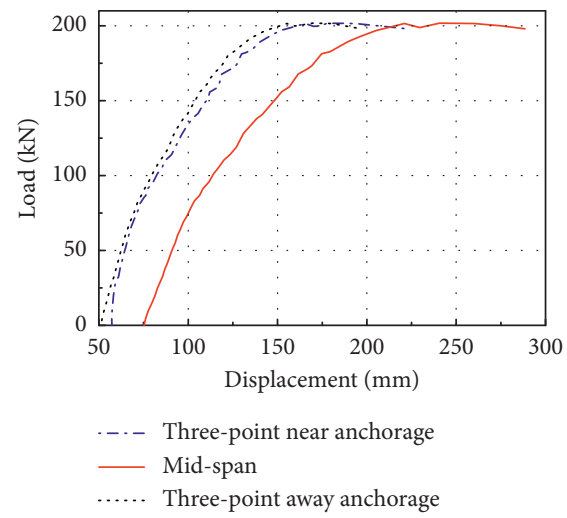

(e)

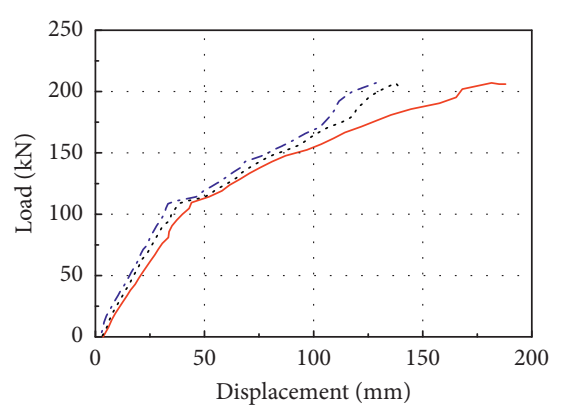

-..- Three-point near anchorage

- Mid-span

..... Three-point away anchorage

(c)

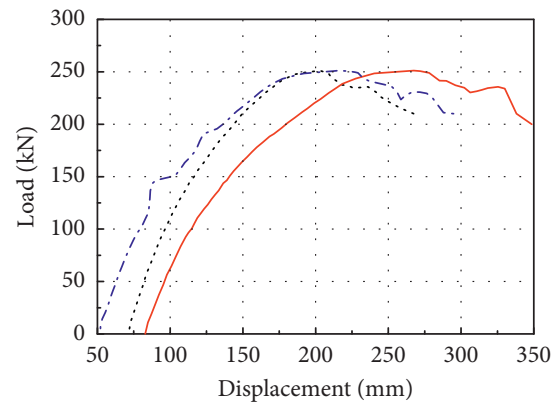

..... Three-point away anchorage

— Mid-span

...- Three-point near anchorage

(f)

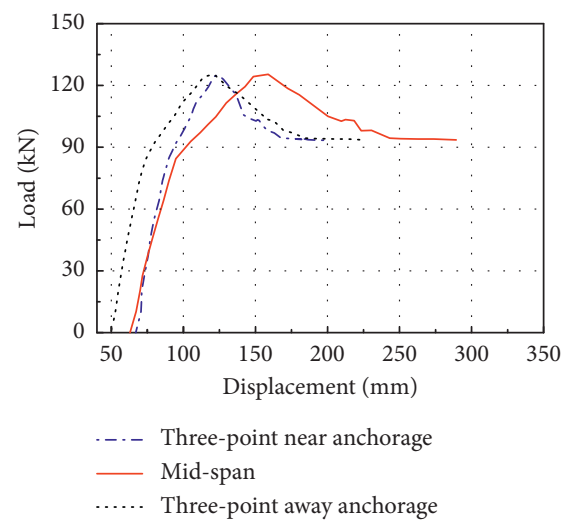

(h)

Figure 9: The load-midspan displacement curves for the specimens. (a) PRPCB1. (b) PRPCB2. (c) PRPCB3. (d) PRPCB4. (e) PRPCB5. (f) PRPCB6. (g) UPRPCB1. (h) UPRPCB2.

point, and the highest temperature of RPC around tendons is lower than $250^{\circ} \mathrm{C}$. Considering that the mechanical performance deteriorated slightly after suffering temperatures below $300^{\circ} \mathrm{C}$, bonding between tendons and surrounding $\mathrm{RPC}$ was stable in this region.

The prestress versus displacement increment curves of tendons in UPRPCB1 and UPRPCB2 are shown in Figure 11(b). The change of prestress with displacement increment contains ascending and descending stages. In the initial term of the test (ascending part), tendons, steel bars, and RPC in tension region provided tension cooperatively, and the prestress of tendons increased with the growth of loading. When steel bars yielded, the ratio of tension sharing with tendons to the whole tension increased; thus, the slope of curves becomes larger. The maximum temperatures of tendons in UPRPCB1 and UPRPCB2 were $525^{\circ} \mathrm{C}$ and $640^{\circ} \mathrm{C}$; the tensile strength approximately declined to $80 \%$ and $60 \%$ of that at room temperature, respectively. After the tendons yield, the displacement and crushing zone height of the beams grew rapidly and prestress in tendons declined significantly. The central longitudinal strain distribution is described in Figure 12. The results show that before 0.8 times 


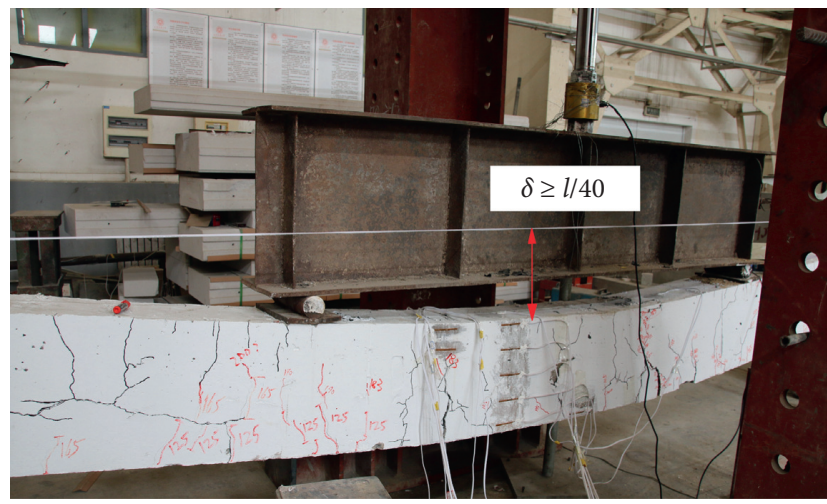

FIGURE 10: Deflection under static load of postfire prestressed RPC beams.

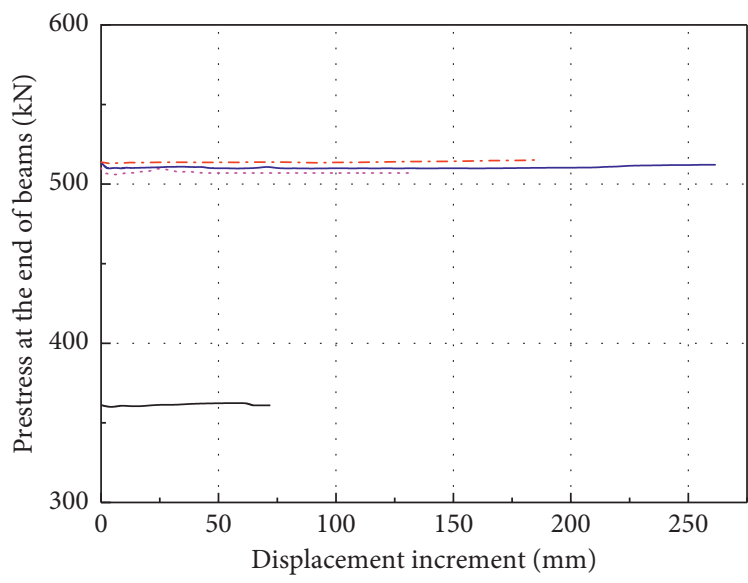

..... PRPCB1

— PRPCB2

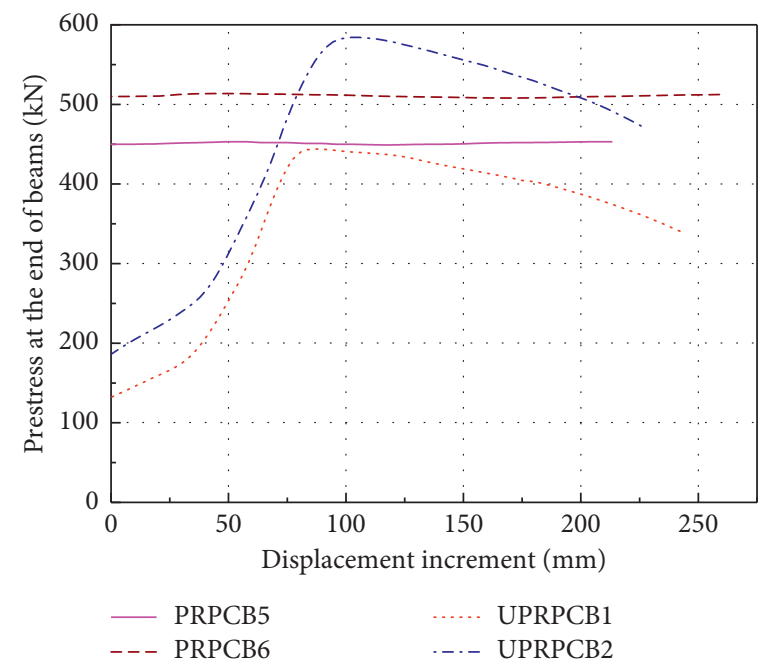

(b)

Figure 11: Changes of prestress of tendons with displacement increment. (a) The first batch test. (b) The second batch test.

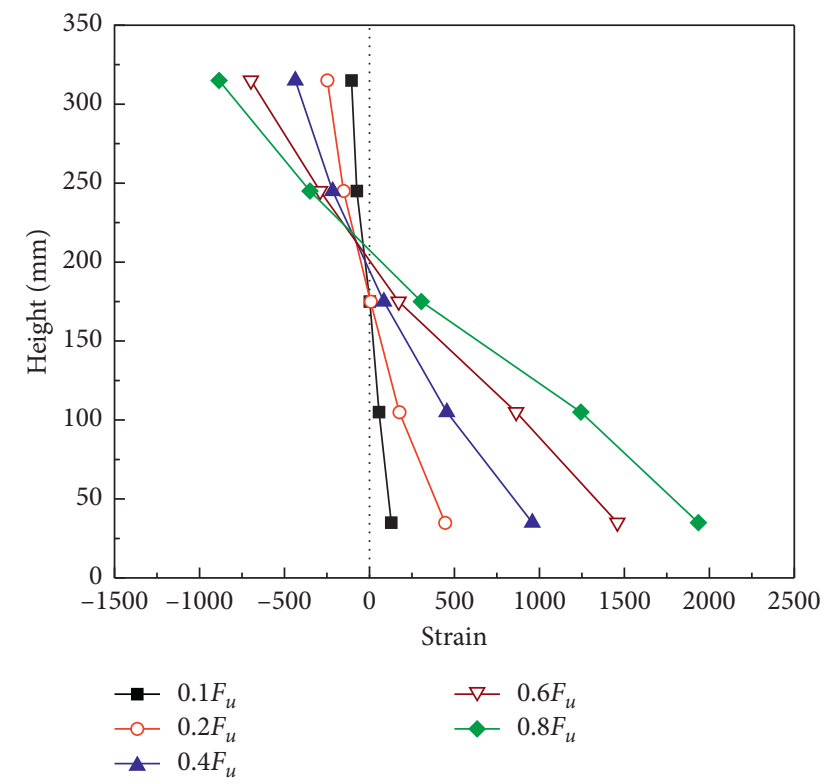

FIgURE 12: Central longitudinal strain distribution. of the ultimate load $F_{\mathrm{u}}$ the strain distribution meets the flat section assumption.

4.4. Failure Modes. The failure modes of the prestressed RPC beams under static loads are shown in Figure 13. Under the action of external loads, the beam has a downward flexural deformation, and the normal section is damaged by the bending. First, the temperature crack widens in the tension zone of the pure bending section, accompanied by new vertical cracks. Afterwards, with the increase of external loads, the vertical cracks in the pure bending section gradually increase and extend upward; small oblique cracks are also added in the bending shear section. When the external load approaches the ultimate load, the change in the load value is reduced and is loaded to the yield value of the steel bar by displacement control. The concrete in the compression zone is crushed, and the specimen is damaged. The higher the temperature the specimen is subjected to, the larger the height of the compression zone. The temperature cracks develop into main cracks during the loading process. 


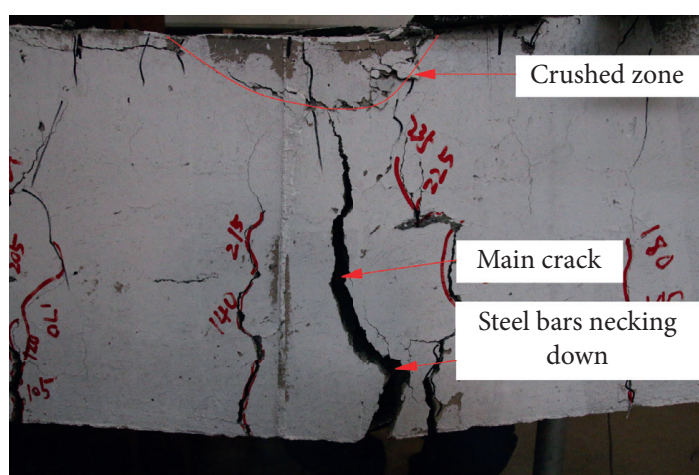

(a)

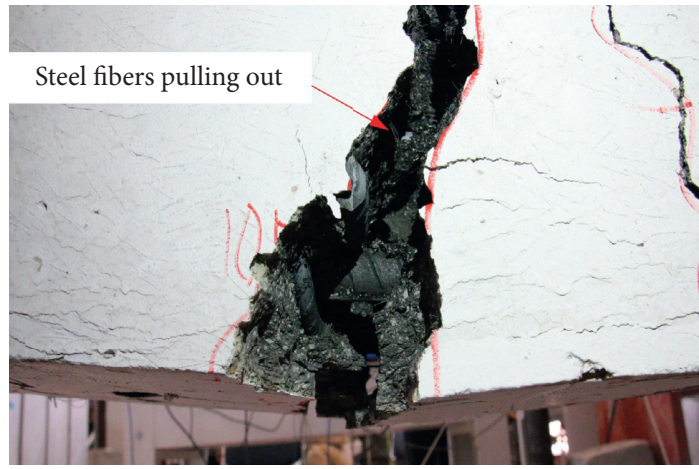

(c)

FIGURE 13: The failure mode of specimens. (a) Main crack.

The new cracks are concentrated at the lower part of the loading point and near the temperature cracks.

After fire, bonded prestressed RPC beams cannot slide due to the adhesive effect between the whole length of the tendons and the concrete contact surface. Its ultimate bearing capacity is larger than that of the RPC beam without bellows. It is seen from the load-midspan displacement that the bonded prestressed RPC beams have better ductility than the postfire prestressed ordinary concrete beam.

The change of the effective prestress at the end of the bonded prestressed RPC beams is not obvious when exposed to fire. The bonding performance of the end RPC and the prestressed tendon is not significantly reduced, while the unbonded effective prestress does present a significant decline. Under the same conditions as the bonded prestressed RPC beams with reinforcement, only one or a few bending cracks appear near the section of the maximum bending moment for the unbonded prestressed RPC beams after fire. With increasing loads, the cracks develop rapidly. The unbonded prestressed RPC beams have better deformation capacity than the bonded prestressed RPC beams, presenting obvious catenary effects.

4.5. Cracking Patterns. Figure 14 and Table 4 illustrate the crack distributions and measured values of the fire damaged specimens under a static load. After the failure, the cracks in the specimens are mainly concentrated at the loading locations of the distribution beam. The fracture orifices usually develop from the temperature cracks that occur in a fire.

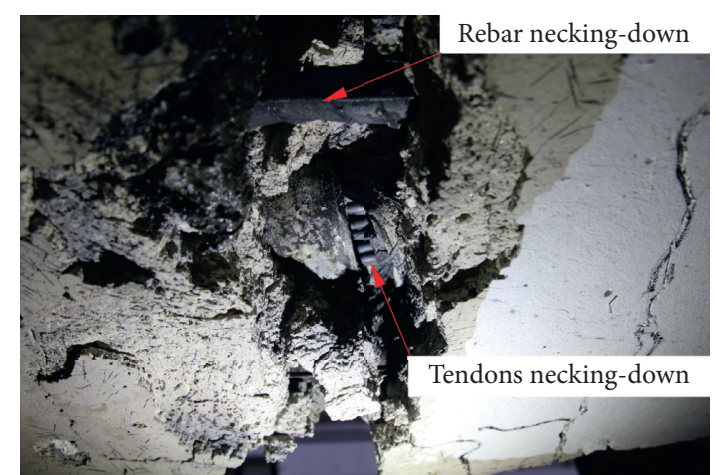

(b)

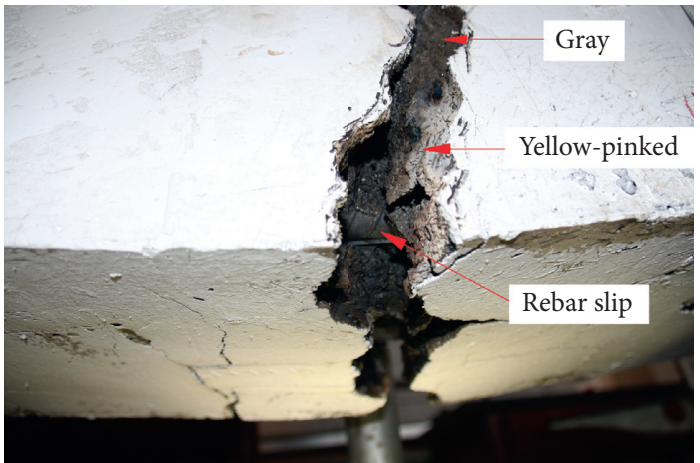

(d)

(b) Steel bar yield. (c) Steel fiber pulling out. (d) Rebar slip.

Under the action of loads, the unbonded specimens have fewer cracks and faster destruction. The crack development of the bonded specimens is slower, and the crack width continues to increase before the beam is completely damaged.

The average spacing of the specimen cracks $l_{m}$ is impacted by numerous parameters including the protective layer thickness, reinforcement ratio, reinforcement diameter, and reinforcement surface properties. Adding steel fiber in RPC concrete can improve the tensile strength of concrete. The bond strength between the concrete and the reinforcing steel bar is roughly proportional to the tensile strength of the concrete. The $l_{m}$ of the reinforced specimens after the fire is greater than that of normal concrete.

\section{Factors Affecting the Postfire Safety of Prestressed RPC Beams}

In order to reveal the postfire safety of prestressed RPC beams, the influences of cover thickness of tendons, load ratio, partial prestressing ratio, and type of tendons are analyzed.

5.1. Effect of Cover Thickness of Tendons $C_{p}$. The test investigates the midspan deformation of the bonded and unbonded specimens with $C_{\mathrm{p}}$ of $35 \mathrm{~mm}, 45 \mathrm{~mm}$, and $55 \mathrm{~mm}$ under the same ultimate loading value after fire, as shown in Figure 15. 


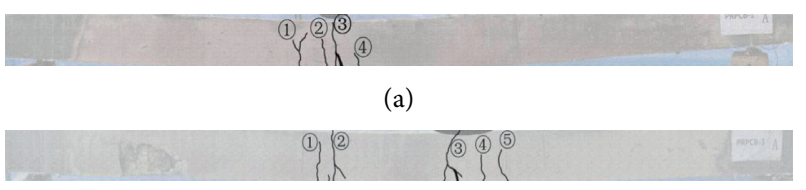

(c)

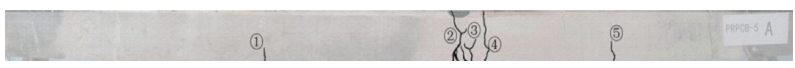

(e)

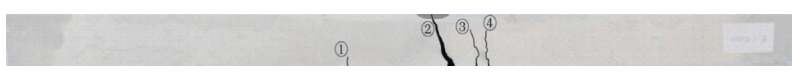

(g)

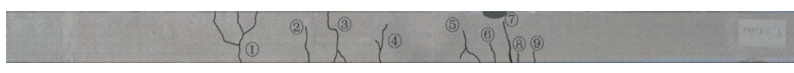

(b)

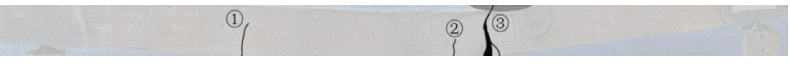

(d)

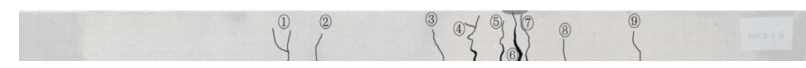

(f)

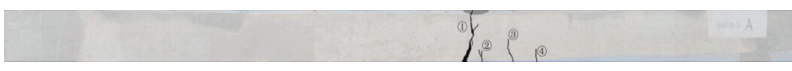

(h)

FIGURE 14: The crack distributions for the specimens. Note that the shadows above the maximum crack of the specimens in the figures show the crushed concrete in the compression zone. (a) PRPCB1. (b) PRPCB2. (c) PRPCB3. (d) PRPCB4. (e) PRPCB5. (f) PRPCB6. (g) UPRPCB1. (h) UPRPCB2.

TABLE 4: Residual bearing capacity results of the specimens.

\begin{tabular}{lcccc}
\hline Specimen no. & $\begin{array}{c}\text { Ultimate bending } \\
\text { moment }(\mathrm{kN} \cdot \mathrm{m})\end{array}$ & Mean crack width $(\mathrm{mm})$ & Mean crack spacing $(\mathrm{mm})$ & Height of RPC crushing zone (mm) \\
\hline PRPCB1 & 226.5 & 7.13 & 131.25 & 20 \\
PRPCB2 & 273 & 4.78 & 267.19 & 26 \\
PRPCB3 & 207 & 11.45 & 342.19 & 30 \\
PRPCB4 & 161.9 & 26.93 & 881.25 & 21 \\
PRPCB5 & 201.7 & 11.01 & 595.59 & 20 \\
PRPCB6 & 251.2 & 8.86 & 309.09 & 55 \\
UPRPCB1 & 105.3 & 14.09 & 331.25 & 30 \\
UPRPCB2 & 125.4 & 6.51 & 175 & 40 \\
\hline
\end{tabular}

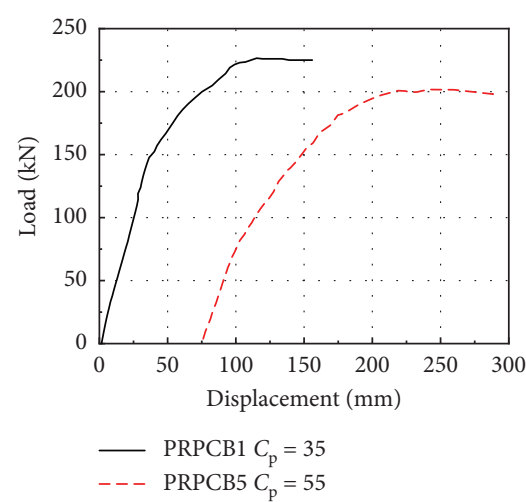

(a)

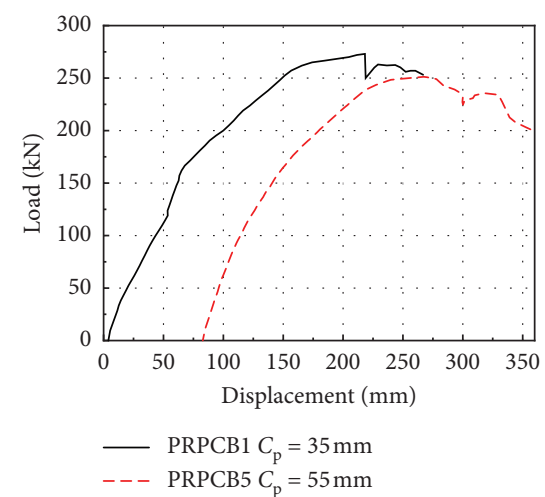

(b)

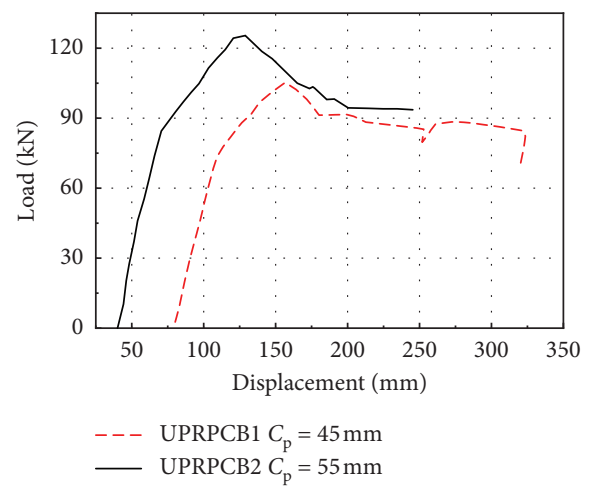

(c)

FIGURe 15: Midspan deformation curves of the specimens with different cover thickness. (a) PRPCB1 and PRPCB5. (b) PRPCB2 and PRPCB6. (c) UPRPCB1 and UPRPCB2.

The ultimate load value of PRPCB1 is $226.5 \mathrm{kN}$, and the ultimate load value of PRPCB5 is $201.7 \mathrm{kN}$. The ultimate bending moment of beams can be obtained from $\left(F_{\mathrm{u}} / 2\right) \times l / 3$, both of which are close. $F_{\mathrm{u}}$ is ultimate load gathered by pressure sensor under hydraulic jack. The inflection point of the load-displacement curve of PRPCB5 is significantly later than that of PRPCB1. The inflection points of PRPCB6 and UPRPCB2 are significantly later than those of PRPCB2 and UPRPCB1, respectively.

The increase in the cover thickness can delay the heating process of the reinforcements. The lower the temperature of the tendons under fire, the smaller the elastic modulus and strength attenuation of the material. In turn, this reduces the stress relaxation and creep, causing a stronger bending deformation capacity. With the increase in the cover thickness, the effective height of the section of the prestressed RPC beams also decreases, which reduces the bending capacity of the specimens after fire.

5.2. Effect of PPR. Figure 16 compares the postfire mechanical behaviors of PRPCB3 and PRPCB4 with different 


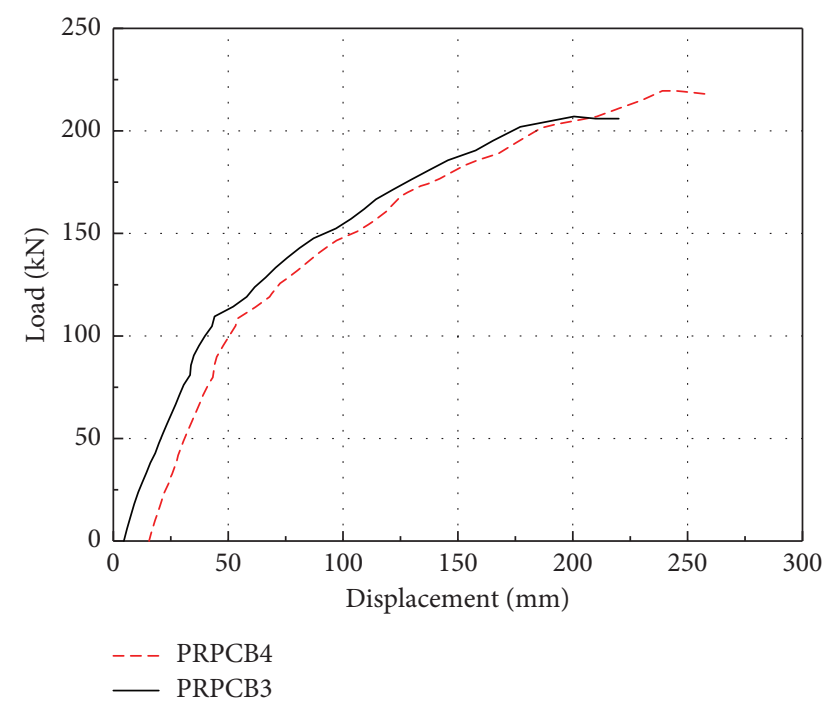

Figure 16: Midspan deformation curves of the specimens with different PPRs.

PPRs. After fire, the midspan displacement has an approximate trend to that of the external load, both of which are bifurcated with slow transitions. The higher the degree of prestress, the greater the proportion of the tendons to the bearing capacity of the prestressed RPC beams. The fire resistance performance of the prestressed steel strand is more sensitive than that of ordinary steel bars, and the material performance degradation is more significant under high temperatures. At $350^{\circ} \mathrm{C}$, the ultimate tensile strength of an $1860 \mathrm{MPa}$ tendon is $50 \%$ of that at room temperature, whereas at $430^{\circ} \mathrm{C}$ the intensity is approximately $60 \%$. Near $520^{\circ} \mathrm{C}$, the strength decreases by $80 \%$. According to the test results, the influence of $\mathrm{PPR}$ on the fire resistance of RPC beams is relatively small.

5.3. Effect of Load Ratio. The load ratio is the ratio between the actual load applied in a test and the corresponding load when the ultimate bearing capacity of the normal section is reached. The mechanical behaviors of the bonded prestressed RPC beams after a fire at the 0.3 and 0.5 initial load ratios are compared and analyzed, as shown in Figure 17.

Within $100 \mathrm{kN}$ of the initial loading, the damage of the mechanical properties of the RPC and reinforcements are not obvious due to the small initial external load. The midspan displacements of PRPCB1, PRPCB2, PRPCB5, and PRPCB6 at the initial load ratios of 0.3 and 0.5 exhibit similar variation trend with the loads. With the increase of the external loads, the midspan deformation growth rate and residual bearing capacity of PRPCB2 and PRPCB6 at the initial load ratio of 0.5 are significantly higher than those of PRPCB1 and PRPCB5 at the initial load ratio of 0.3. This is mainly because the test specimen at the initial load level of 0.5 produces a higher stress effect in comparison with the initial load ratio of 0.3 . In addition, a larger additional deformation is produced due to the decrease of the elastic modulus of the material and the creep at high temperatures.

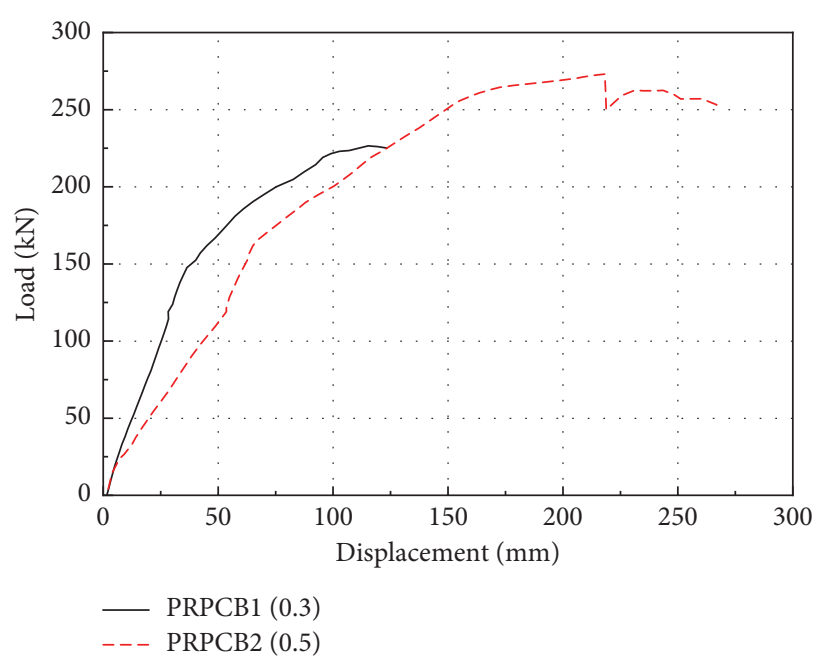

(a)

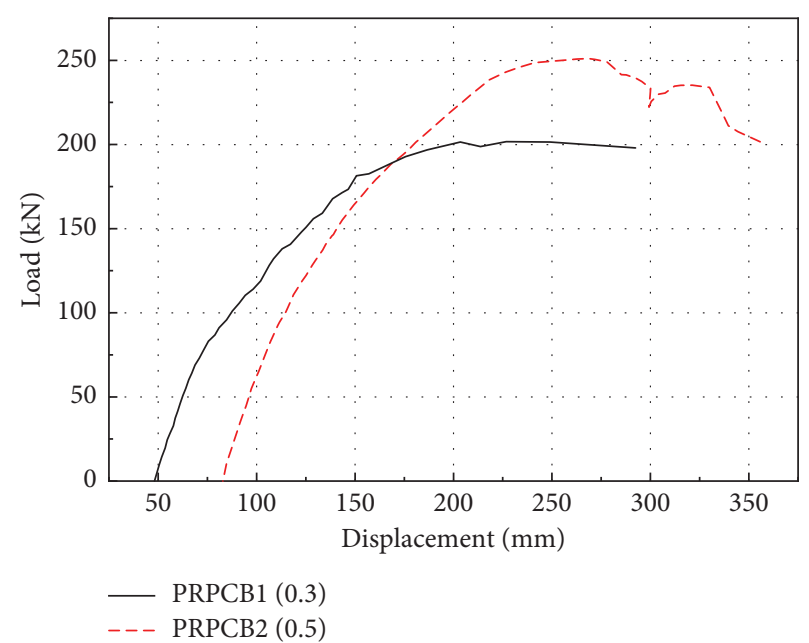

(b)

FIGURE 17: Midspan deformation curve under different load ratios. (a) PRPCB1 and PRPCB2. (b) PRPCB5 and PRPCB6.

The influence of the initial load ratios from 0.3 to 0.5 of the bonded prestressed RPC beams is greater than that of the cover thickness of tendons from $35 \mathrm{~mm}$ to $55 \mathrm{~mm}$. Therefore, the load ratio is one of the key factors influencing the postfire safety of prestressed RPC beams.

5.4. Effect of Bonded/Unbonded Tendons. For unbonded prestressed RPC beams, because there is no bonding between the tendons and the surrounding concrete, one or a few vertical cracks usually appear in the section of the maximum bending moment. With the increase in the load, the width and height of the cracks increase rapidly. With the evolution of the cracks, the concrete is crushed and brittle failure occurs on the beam. The residual bending capacities of PRPCB6 and PRPCB2 in Figure 18 are $251.2 \mathrm{kN} \cdot \mathrm{m}$ and $125.4 \mathrm{kN} \cdot \mathrm{m}$, respectively.

The increase of the deflection of unbonded prestressed RPC beams is more likely to form larger flexural cracks. The temperature in the cracks increases rapidly, resulting in 


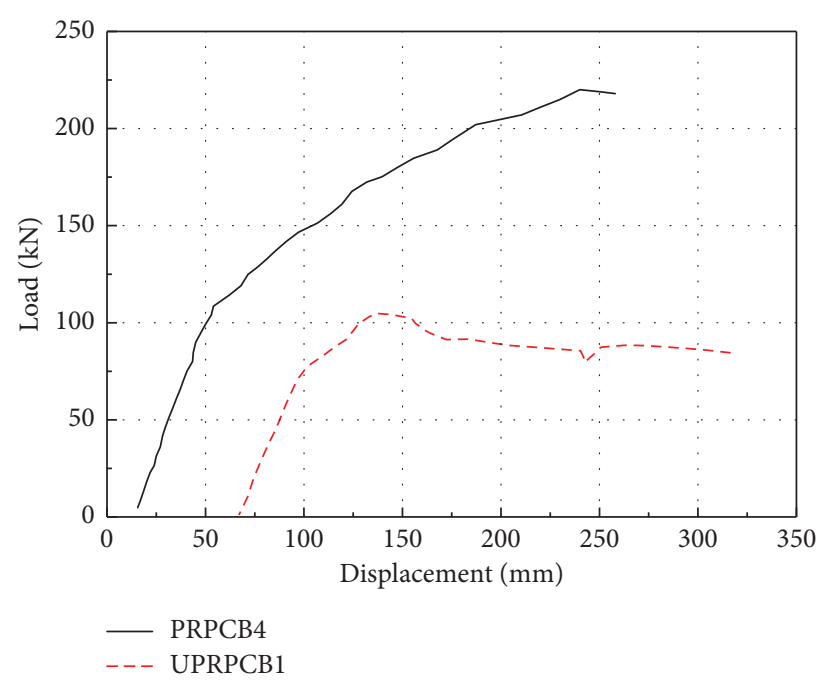

(a)

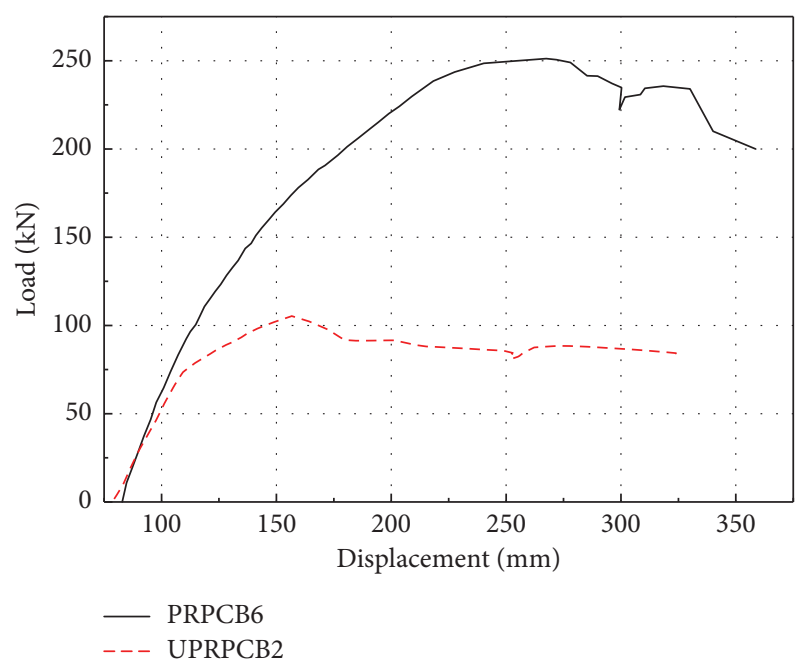

(b)

FIgURE 18: The effect of bonding on the midspan deformation of the specimens. (a) PRPCB4 and PRPCB2. (b) PRPCB5 and PRPCB6.

serious loss in the high-temperature properties of the tendons. Although bonded tendons, such as unbonded prestressed tendons, produce substantial high-temperature creep and free expansion with increases in temperature, the tendons slip in the bellows. This leads to the loss and release of effective prestresses. The postfire safety of bonded prestressed RPC beams is superior than that of unbonded prestressed RPC beams.

\section{Conclusions}

(1) The postfire safety of prestressed RPC beams progressively decreases with the increase of the fire's duration. Due to the prestress inside the beam, the load-deflection curve of the prestressed RPC beams shows a three-section polyline variation rule after the fire damage occurs. The polyline has obvious boundary points corresponding to the crack expansion of the RPC and the yield of the tendons.

(2) There is a strong catenary effect in the deformation of the prestressed RPC beams after fire damage occurs. The midspan deformation under the ultimate load is approximately $1 / 40$ of the effective span, which is significantly larger than $1 / 150$ at room temperature.

(3) For the prestressed RPC beams designed according to underreinforced beam, the failure process presents the original failure characteristics according to the load-deflection curves after fire. However, compared with beams at room temperature, the height of RPC crushing zone on the top of the beam is smaller, and the crack on the bottom of the beams is larger. From the failure appearance, the failure mode belongs to a less-reinforced beam.

(4) Load ratio, cover thickness, and type of tendons are key factors influencing the postfire safety of prestressed RPC beams. With the same design parameters, the postfire safety of bonded prestressed RPC beams is superior than that of unbonded prestressed RPC beams.

\section{Data Availability}

All data used to support the findings of this study are included within the article.

\section{Conflicts of Interest}

The authors declare that they have no conflicts of interest.

\section{Acknowledgments}

The work in this paper was supported by the National Natural Science Foundation of China (nos. 51878399 and 51408341).

\section{References}

[1] P. Richard and M. Cheyrezy, "Composition of reactive powder concretes," Cement and Concrete Research, vol. 25, no. 7, pp. 1501-1511, 1995.

[2] D. Wang, C. Shi, Z. Wu, J. Xiao, Z. Huang, and Z. Fang, “A review on ultra high performance concrete: part II. hydration, microstructure and properties," Construction and Building Materials, vol. 96, no. 15, pp. 368-377, 2015.

[3] D.-Y. Yoo and Y.-S. Yoon, "A review on structural behavior, design, and application of ultra-high-performance fiberreinforced concrete," International Journal of Concrete Structures and Materials, vol. 10, no. 2, pp. 125-142, 2016.

[4] K. Roy, J. B. P. Lim, H. H. Lau et al., "Collapse behaviour of a fire engineering designed single-storey cold- formed steel building in severe fires," Thin-Walled Structures, vol. 142, no. 9, pp. 340-357, 2019.

[5] M. Moradi, H. Tavakoli, and G. Abdollahzadeh, "Probabilistic assessment of failure time in steel frame subjected to fire load under progressive collapses scenario," Engineering Failure Analysis, vol. 102, no. 8, pp. 136-147, 2019. 
[6] M. Fragiacomo, A. Menis, I. Clemente et al., "Fire resistance of cross-laminated timber panels loaded out of plane," Journal of Structural Engineering, vol. 139, no. 12, pp. 323-335, 2013.

[7] S. E. Quiel and S. M. Marjanishvili, "Fire resistance of a damaged steel building frame designed to resist progressive collapse," Journal of Performance of Constructed Facilities, vol. 26, no. 4, pp. 402-409, 2012.

[8] R. Sun, Z. H. Huang, Z. Huang, and I. W. Burgess, "The collapse behaviour of braced steel frames exposed to fire," Journal of Constructional Steel Research, vol. 72, no. 5, pp. 130-142, 2012.

[9] D. Lange, C. Röben, and A. Usmani, "Tall building collapse mechanisms initiated by fire: mechanisms and design methodology," Engineering Structures, vol. 36, no. 5, pp. 90103, 2012.

[10] I. Fletcher, S. Welch, J. Torero, R. Carvel, and A. Usmani, "Behaviour of concrete structures in fire," Thermal Science, vol. 11, no. 2, pp. 37-52, 2007.

[11] Y. N. Chan, G. F. Peng, and M. Anson, "Residual strength and pore structure of high-strength concrete and normal strength concrete after exposure to high temperatures," Cement and Concrete Composites, vol. 21, no. 1, pp. 23-27, 1999.

[12] M. Garlock, I. Paya-Zaforteza, V. Kodur, and L. Gu, "Fire hazard in bridges: review, assessment and repair strategies," Engineering Structures, vol. 35, no. 2, pp. 89-98, 2012.

[13] V. K. R. Kodur and A. Agrawal, “An approach for evaluating residual capacity of reinforced concrete beams exposed to fire," Engineering Structures, vol. 110, no. 5, pp. 293-306, 2016.

[14] J. Gales, L. A. Bisby, and M. Gillie, "Unbonded post tensioned concrete in fire: a review of data from furnace tests and real fires," Fire Safety Journal, vol. 46, no. 4, pp. 151-163, 2011.

[15] Y. Yang, S. Feng, Y. Xue, Y. Yu, H. Wang, and Y. Chen, "Experimental study on shear behavior of fire-damaged reinforced concrete T-beams retrofitted with prestressed steel straps," Construction and Building Materials, vol. 209, no. 6, pp. 644-654, 2019.

[16] F. Aslani, "Prestressed concrete thermal behaviour," Magazine of Concrete Research, vol. 65, no. 3, pp. 158-171, 2013.

[17] J. Gales, L. A. Bisby, C. MacDougall, and K. MacLean, "Transient high-temperature stress relaxation of prestressing tendons in unbonded construction," Fire Safety Journal, vol. 44, no. 4, pp. 570-579, 2009.

[18] W. Z. Zheng, X. M. Hou, and K. Yan, High Temperature Performance and Fire Resistance Design of Prestressed Concrete, Harbin Institute of Technology Press, Harbin, China, 2013.

[19] W. Zheng, H. Li, and Y. Wang, "Compressive behaviour of hybrid fiber-reinforced reactive powder concrete after high temperature," Materials \& Design, vol. 41, pp. 403-409, 2012.

[20] W. Zheng, B. Luo, and Y. Wang, "Compressive and tensile properties of reactive powder concrete with steel fibres at elevated temperatures," Construction and Building Materials, vol. 41, pp. 844-851, 2013.

[21] G. F. Wang and J. Yang, "Residual mechanical properties and explosive spalling behavior of ultra-high-strength concrete exposed to high temperature," Journal of Harbin Institute of Technology, vol. 24, no. 4, pp. 62-70, 2017.

[22] J. Zhao, J.-J. Zheng, G.-F. Peng, and K. van Breugel, “A mesolevel investigation into the explosive spalling mechanism of high-performance concrete under fire exposure," Cement and Concrete Research, vol. 65, pp. 64-75, 2014.

[23] Y.-S. Tai, H.-H. Pan, and Y.-N. Kung, "Mechanical properties of steel fiber reinforced reactive powder concrete following exposure to high temperature reaching $800^{\circ} \mathrm{C}$," Nuclear Engineering and Design, vol. 241, no. 7, pp. 2416-2424, 2011.

[24] C.-T. Liu and J.-S. Huang, "Fire performance of highly flowable reactive powder concrete," Construction and Building Materials, vol. 23, no. 5, pp. 2072-2079, 2009.

[25] M. F. Day, E. A. Jenkinson, and A. I. Smith, "Effect of elevated temperatures on high-tensile-steel wires for prestressed concrete," Proceedings Instituting of Civil Engineers, vol. 16, no. 5, pp. 55-70, 1960.

[26] Z. H. Guo and X. D. Shi, Experiment and Calculation of Reinforced Concrete at Elevated Temperatures, Tsinghua University Press, Beijing, China, 1st edition, 2003.

[27] X. Hou, W. Zheng, V. Kodur, and H. Sun, "Effect of temperature on mechanical properties of prestressing bars," Construction and Building Materials, vol. 61, no. 30, pp. 2432, 2014.

[28] ISO 834-1, "Fire resistance tests-elements of building construction-part 1: general requirements," International Standard ISO 834, Geneva, Switzerland, 1999.

[29] W. Zheng, L. Li, and S. Lu, "Experimental research on mechanical performance of normal section of reinforced reactive powder concrete beam," Journal of Building Structures, vol. 32, no. 6, pp. 125-134, 2011. 